\title{
What do users of reduced-fat dairy products know about the fat in their diets?†
}

\author{
Stephanie Harper* $¥$ and Ingrid HE Rutishauser \\ School of Nutrition \& Public Health, Deakin University, Geelong 3217, Victoria, Australia
}

\begin{abstract}
Objectives: To assess the fat intake and knowledge about the fat content of foods consumed by a sample of self reported users of reduced-fat dairy products.

Design: Cross-sectional study of a population-based sample of women shoppers.

Setting: A small, rural town (population approximately 6000) in central Victoria, Australia.

Subjects: Seventy-eight women aged 25-50 years, who regularly used at least one reduced-fat dairy product.

Results: Mean reported intake of total fat was lower while intake of dairy fat was similar to that of a national sample of women of the same age both in the whole sample and when under-reporters were excluded. The ability to identify major sources of fat in the diet as reported appeared to be limited. Less than half of the subjects were able to correctly estimate the fat content of reduced-fat dairy products relative to regular products and about one quarter of subjects reported replacing one kind of oil or fat with another as a strategy to reduce fat intake. Subjects were generally aware of the need to 'eat less fat' but few could articulate specific recommendations. A number of subjects reported using low fat diets to control their weight but few subjects appeared to understand the connection between fat intake and energy intake.

Conclusions: The findings of this study raise important questions about how nutrition advice is understood and implemented by consumers, particularly the message to reduce fat intake and the role of energy balance in weight management. They also highlight the difficulty of interpreting information on food intake, in subjects who have modified their diet by reducing intake of specific foods.
\end{abstract}

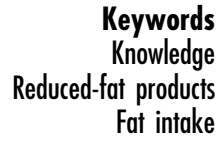

Keywords Fat intake
Lower fat alternatives (LFAs) to regular dairy products, such as milk, yoghurt and cheese are promoted ${ }^{1}$ as a means of reducing dietary fat and these products have gained considerable acceptance, particularly amongst women $^{2-4}$. Investigation of consumers' knowledge of the fat content of foods 5,6 , and its relationship with fat intake $^{7,8}$ has, however, yielded inconsistent results possibly caused by the lack of 'relevant' knowledge measures ${ }^{8}$.

Research suggests that people are not aware of the amount and nature of fats in some common foods ${ }^{5}$, and tend to underestimate their fat consumption and overestimate the extent to which they have reduced

†This research was conducted as part of the corresponding author's Masters project, prior to her commencing employment at the AntiCancer Council. It was jointly funded by the corresponding author and Deakin University.

¥Current address: Anti-Cancer Council of Victoria, 1 Rathdowne St, Carlton, Victoria 3053, Australia. their intake $\mathrm{e}^{9-11}$. However, this may vary between countries $^{12}$.

Australian data ${ }^{3}$ indicate that at least some women who used LFAs increased their intake of other high fat and/or energy foods and suggest that concepts such as energy balance are not generally well understood. Some people may believe that they can consume 'as much (low fat product) as they like', without considering total energy intake $^{13}$. Misleading or unclear messages in food advertising and labelling may also contribute to confusion ${ }^{14,15}$ since even well educated consumers have difficulty interpreting food labels ${ }^{16}$.

In the present study, women 25-50 years of age who regularly used reduced-fat milk, yoghurt or cheese completed a questionnaire about their usual food intake and were asked to identify their major sources of fat. The purpose of the study was to assess subjects' knowledge about fat and to find out whether the use of LFAs was associated with a lower fat intake than in a nationally 
representative sample of women of similar age. The study was approved by the Ethics Committee of the Faculty of Health and Behavioural Sciences, Deakin University.

\section{Methods}

\section{Subjects}

The study was conducted in Kyneton (population approximately 6000), located $85 \mathrm{~km}$ north of Melbourne. The town is a commercial centre for the local farming community, and home to professional people working outside the area.

\section{Subject recruitment}

Subjects were recruited, over a period of 4 weeks in August and September 1997, from female shoppers leaving/entering the only supermarket. Recruitment took place during the times and days when the supermarket was busiest. Subjects were recruited on 13 occasions and each recruitment period lasted about 2.5 hours. Approximately the same amount of time was spent outside each of the two entrances to the supermarket. When more than one possibly eligible shopper arrived at about the same time, the first or closest individual was approached. Each person approached was asked whether they:

- used at least one low-fat dairy product (milk, yoghurt or cheese) per fortnight

- were aged between 25 and 50 years

- had at least one child living at home

- lived locally (i.e. within a $40 \mathrm{~km}$ radius of the town)

- had been born in Australia, the UK or New Zealand.

A plain language statement explaining the nature and requirements of the study was read to all eligible women. Those agreeing to participate were then given a copy of the statement and the consent form, and told that they would be contacted by phone within 3-4 weeks to arrange a meeting.

At the initial meeting subjects were asked to provide socio-demographic data and told how to complete the FFQ.

If the subject was not at home at the prearranged time, the questionnaire and a stamped, addressed envelope, together with written instructions and a contact telephone number, were left at the subject's home or other agreed location. A follow-up telephone call was made after 6 weeks if the FFQ had not been returned. After mid-March 1998, it was assumed the subject no longer wished to participate.

\section{Data collection}

Data obtained from participants included age, sex, marital status, number of children living at home, education, occupation, employment status and household income.

Information on usual food intake over the preceding 3 months was obtained using a meal-based FFQ which has previously been described and calibrated in a population-based sample of Victorian adults ${ }^{16,17}$. The FFQ also included questions on methods of food preparation and on the types and amounts of fat spread and low fat dairy products used.

Each subject's FFQ was analysed to develop a list of 15 foods/food groups, which included all their major sources of fat. Total energy and fat intake and percent energy from fat were calculated using a computer program (SOFFA, Computer Models, Cottesloe, W.A. 6012, Australia) based on NUTTAB, the Australian food composition database produced by the National Food Authority. For each food/food group on the list, the number of 'serves' per week was estimated based on the amount (generally household measures) of the food typically consumed by the subject. The list did not include any rarely eaten foods. The fat in spreads eaten together with bread and the fat in milk consumed with breakfast cereal were included with bread and breakfast cereal, respectively. The list of foods together with the number of serves of each eaten per week was displayed on a card and used as the basis for the interview to assess each subject's knowledge about LFAs and other sources of fat in their diet.

All interviews were conducted by one of the authors (SH) and on average lasted approximately 30 minutes. During the interview subjects were asked to identify their major sources of fat from the card and to give reasons for their choice. Subjects were then asked about their reasons for use of LFAs and their strategies for reducing fat intake. They were also asked to estimate (to the nearest 25\%) the relative fat content of reduced-fat dairy products that they used and to rate the fat content of their own diets on a continuous scale from 'much too low' to 'much too high'. Responses were recorded on a standard form using either pre-determined response categories or verbatim answers as appropriate. The full interview schedule is available from the authors.

\section{Statistical analysis}

The two-sample, two-tailed $t$-test was used to compare means for continuous variables between two groups and one-way analysis of variance to compare multiple means. Chi-square was used to test for associations between fat intake and categorical variables. Statistical significance was evaluated at the $P=0.05$ level

\section{Results}

\section{Response rates}

Of the 517 female shoppers approached, 250 were eligible for the study and of these 120 agreed to participate. When contacted, 12 of those recruited were no longer willing or able to participate, a further 17 failed to return a questionnaire and 13 withdrew when followup phone calls were made. One subject could no longer 
Table 1 Demographic profile of subjects $(n=78)$ participating in the study

\begin{tabular}{ll}
\hline Characteristic & Data \\
\hline Age (years) & \\
Body mass index ${ }^{*}\left(\mathrm{~kg} \mathrm{~m}^{-2}\right)$ & $38.5(6.0)$ \\
Proportion with: & $24.5(3.6)$ \\
$\geq 2$ children at home & $68 \%$ \\
Annual family income $>\$ 30,000$ & $72 \%$ \\
Post-secondary qualifications & $55 \%$ \\
Employment outside the home & $68 \%$ \\
\hline
\end{tabular}

* Values are the mean with standard deviation in parentheses.

be contacted, and another failed to keep an interview appointment.

The final response rate was 31\% of those who were eligible, and $65 \%$ of the eligible subjects who agreed to participate. Questionnaire and interview data were obtained for 78 subjects.

\section{Demographic characteristics}

Table 1 summarizes the demographic data for the study subjects. The group was similar to the Kyneton population in relation to educational level and employment status. At the 1996 Census, approximately 54\% of women aged 25-44 years in Kyneton had a post-secondary qualification, and $61 \%$ were employed either full or part-time.

Figures for household income in the present study (28\% $\leq$ AUD\$30,000 per annum) are not directly comparable with 1996 Census data which indicated that 26\% of families with dependent children had an annual income $<$ AUD $\$ 26,000$ and 44\% an income of $<$ AUD\$36,000.

The proportion of women with a body mass index (BMI) $>25(35 \%)$ was about 5\% greater than that reported in the 1995 National Health Survey ${ }^{18}$. However, this difference may well be due solely to the fact that in the
National Health Survey BMI could not be calculated for $10 \%$ of the women, compared with only $5 \%$ in this study.

\section{Food intake}

The mean $( \pm S D)$ reported energy intake for the whole sample was $7.48 \pm 2.14 \mathrm{MJ} \mathrm{day}^{-1}$, fat intake $59.0 \pm$ $25.7 \mathrm{~g} \mathrm{day}^{-1}$ and dairy fat intake $12.4 \pm 9.9 \mathrm{~g} \mathrm{day}^{-1}$. The average percentage of total energy intake derived from fat was $28.4 \pm 6.5 \%$.

Mean energy intake (EI) was equivalent to only 1.29 basal metabolic rate (BMR), estimated from weight and age $^{19}$ and less than 1.35 BMR for 51 of the 78 subjects, which suggests a high prevalence of either dieting or under-reporting $^{20}$. Twenty-four subjects $(31 \%$ of the sample) reported that they were trying to lose weight and of these 17 reported usual energy intakes of $<1.35$ BMR. The 32 subjects with EI/BMR $<1.35$ who were not trying to lose weight were classified as under-reporters and where appropriate are identified separately or omitted from the analysis.

\section{Ability to identify major sources of fat}

Table 2 shows, for foods which were consumed by at least two-thirds of the subjects, the percentage of consumers for whom they were a major source of fat and the percentage of consumers who overlooked these foods as a major source of fat in their diet. A subject was identified as a consumer if the food was eaten at least once per month and a food as a major source of fat if it was one of the subject's four main sources of dietary fat based on the FFQ.

Seven foods (spreads on bread, milk with cereal, meat dishes, cheese, mixed dishes, drinks containing milk, chicken/fish) were reported on the FFQ as a major source of fat by at least $25 \%$ of consumers and only cheese was correctly identified by the majority of these subjects. The foods most often incorrectly identified as a major source

Table 2 Ability of consumers to identify their major* sources of fat

Percent of consumers

\begin{tabular}{|c|c|c|c|c|c|}
\hline \multirow[b]{2}{*}{ Food/food group } & \multirow[b]{2}{*}{$\begin{array}{c}\text { No. of } \\
\text { consumers }\end{array}$} & \multicolumn{4}{|c|}{ Percent of consumers } \\
\hline & & $\begin{array}{c}\text { For whom } \\
\text { food was a } \\
\text { major source of } \\
\text { fat in FFQ }\end{array}$ & $\begin{array}{l}\text { Overlooking as } \\
\text { a major source } \\
\text { of fat at interview }\end{array}$ & $\begin{array}{l}\text { Correctly identifying } \\
\text { as a major source } \\
\text { of fat at interview }\end{array}$ & $\begin{array}{c}\text { Incorrectly identifying } \\
\text { as a major source } \\
\text { of fat at interview }\end{array}$ \\
\hline Spread on bread & 58 & 93 & 64 & 29 & 1 \\
\hline Meat dishes & 71 & 68 & 41 & 27 & 3 \\
\hline Cereal and milk & 63 & 40 & 37 & 3 & 8 \\
\hline Cheese & 73 & 38 & 16 & 22 & 22 \\
\hline Mixed dishes & 74 & 32 & 27 & 5 & 12 \\
\hline Milk in drinks & 75 & 27 & 25 & 2 & 0 \\
\hline Chicken/fish & 67 & 25 & 25 & 0 & 0 \\
\hline Cakes/desserts & 62 & 19 & 6 & 13 & 21 \\
\hline Confectionery/snack foods & 56 & 18 & 5 & 13 & 21 \\
\hline Prepared meats & 64 & 16 & 3 & 13 & 22 \\
\hline Sauces/dressings & 74 & 14 & 11 & 3 & 5 \\
\hline Egg/egg dishes & 56 & 9 & 7 & 2 & 7 \\
\hline
\end{tabular}

* A major source was defined as one of the four main sources of fat estimated from the FFQ.

This table only includes foods consumed by at least two-thirds of subjects. 
Table 3 Proportion of subjects correctly identifying at least one major fat source in their diet classified by reported level of fat intake (SEM shown in parentheses)

\begin{tabular}{lcccl}
\hline $\begin{array}{l}\text { Reported fat } \\
\text { intake }\left(\mathrm{g} \mathrm{day}^{-1}\right) \\
\text { from FFQ }\end{array}$ & $\begin{array}{c}\text { No. of } \\
\text { subjects }\end{array}$ & $\begin{array}{c}\text { Percent able } \\
\text { to identify a } \\
\text { major source of fat }\end{array}$ & $\begin{array}{c}\text { Mean BMI } \\
\left(\mathrm{kg} \mathrm{m}^{-2}\right)\end{array}$ \\
\hline$<40$ & 15 & 67 & $25.5(1.2)$ & $\begin{array}{c}\text { Most common } \\
\text { major fat sources for group }\end{array}$ \\
40 to $<60$ & 26 & 69 & $24.8(0.7)$ & Spreads on bread, meat dishes, cheese, yoghurt \\
60 to $<80$ & 25 & 32 & $23.6(0.6)$ & Spreads on bread \\
$\geq 80$ & 11 & 27 & $24.0(0.8)$ & Spreads on bread \\
\hline
\end{tabular}

of fat at interview, but not identified as a main source by the FFQ were: cheese, prepared meats, cakes/desserts and confectionery/snack foods. The findings were essentially similar with under-reporters excluded.

Sixty-four subjects (82\%) correctly identified at least one and 57 subjects (73\%) identified two of their four main reported fat sources. Table 3 shows that the amount of fat reported was related to subjects' ability to identify their major source(s) of fat. On average, two out of three subjects with a total fat intake of $60 \mathrm{~g} \mathrm{day}^{-1}$ or less, correctly identified at least one of their major sources of dietary fat, whereas only one in three of those whose reported intakes were greater than $60 \mathrm{~g}$ day $^{-1}$ were able to do this. Although the average BMI was also higher for those with fat intakes greater than $60 \mathrm{~g} \mathrm{day}^{-1}$, this trend was not statistically significant. Fat spreads used on bread were the most common major source of fat for all except the lowest fat intake group.

\section{Strategies for reducing fat intake}

All subjects reported using at least one LFA per fortnight and 66 subjects (85\%) indicated that they used LFAs in order to reduce fat intake. Other reasons given for using LFAs included: to control weight (23 subjects), taste (14 subjects) and general health (12 subjects). Energy intake, total fat intake and the EI/BMR ratio were all highly correlated $(>0.7)$ with dairy fat intake in the whole sample and when under-reporters were excluded but not in under-reporters $(<0.4)$. Nineteen subjects $(24 \%)$ reported replacing one kind of oil or fat spread with another as a strategy to reduce fat intake.

Thirty-four subjects (44\%) reported eliminating (27) or reducing (7) their intake of full-cream dairy products during the 2 years prior to the interview. The only other fat sources for which a significant number of subjects reported a change were: fat spreads (22 subjects), cakes/ desserts (12) and biscuits (12). In general, intake of these sources was reduced rather than eliminated.

When asked if there were other strategies they would be willing to employ if a further reduction in fat intake was required, 16 subjects (20\%) considered that they were already doing enough. The remaining subjects most frequently mentioned avoiding or reducing their use of fat spreads, eating less cakes, desserts and confectionery (11 subjects) or eating less red and/or prepared meat (7 subjects) as strategies they would use to further reduce fat intake.

\section{Knowledge about the fat and energy content of foods}

Knowledge of the fat content of reduced-fat milk relative to that of the regular product was better ( $42 \%$ of subjects correct) than for cheese (25\%) and yoghurt (20\%). These proportions did not increase when data for subjects using LFAs for reasons other than to reduce fat intake were excluded.

When asked about the energy content of the low-fat product, 24 subjects (31\%) said the energy content was about the same, and 10\% believed there was more energy in the LFA than in the regular product. Eleven subjects said that they did not know.

Forty-eight subjects (62\%) believed that the energy content of a food was related to fat content, 18 thought the energy content of a food was not affected by its fat content and a further 12 said that they did not know. Only four subjects were aware that fat provided more energy per gram than carbohydrate, and only one knew that fat provided about twice the energy of carbohydrate. Sixteen subjects (20\%) thought that all foods that were high in fats were also high in energy while six subjects stated that high fat foods provided less (or low fat foods provided more) energy.

The term 'energy', in the context of food, was most frequently associated with specific, high carbohydrate foods such as pasta, fruit and vegetables (28\% of the group), sugar (27\%), or carbohydrates in general (24\%). Only 11 subjects (14\%) mentioned kilojoules or calories and only two subjects linked energy with fat.

The large proportion (78\%) of subjects who reported trying to control weight was not unexpected, given that they were selected on the basis of their regular use of reduced-fat dairy products. Nevertheless, only 23 subjects (29\%) reported using LFAs specifically for this purpose.

Of the 24 subjects who were trying to lose weight, only four said that they considered energy, kilojoules or calories in food selection. Reducing fat intake was generally seen as 'easier' or more convenient than 'counting calories' but only three claimed to have lost weight just by reducing fat intake. Five subjects commented that low-fat diets were part of an overall lifestyle change (for them and their families). 


\section{Knowledge about recommendations for fat intake}

Sixty-five subjects (83\%) claimed to be aware that there were national recommendations for fat intake, but only two could state them. Nine subjects quoted values ranging from 18 to $40 \mathrm{~g} \mathrm{day}^{-1}$. Seven subjects referred to the 'Food Pyramid' and five to the National Heart Foundation 'tick' 'тм.

\section{Discussion}

The lower intake of total energy and fat in the study group compared with the general population was not due to a lower intake of dairy fat but, in part at least, to underreporting of food intake. However, even with underreporters excluded, the percentage energy from fat was still lower $(30 \%)$ than in the general population $(33 \%)^{21}$. This suggests that the study group had a tendency to under-report sources of fat other than dairy products. Cakes/desserts, confectionery/snacks and prepared meats were frequently identified at interview, but not by the FFQ, as major sources of fat, suggesting that the amounts of these foods may have been under-reported. However, the majority of women in the present study clearly did not recognize at interview the significant contribution that fat spreads on bread, meat dishes and milk on cereals can make to fat intake (Table 2).

Overweight subjects ${ }^{22-24}$ and those trying to lose or control weight $^{22}$ have been found to be more likely to under-report intake. The $35 \%$ of women with a BMI $>25$ probably contributed to the low energy and fat intake reported in the present study; however, other factors were also involved since a proportion of women with a BMI $<25$ also had an EI/BMR $<1.35$.

Knowledge about the amount of fat in reduced-fat milk was better than that for yoghurt and cheese. This is most likely due to the much greater variety of yoghurt and cheese products, for which the reduction in fat content can range from 2 to $27 \%$ of that in the regular version. The finding that about one quarter of the subjects did not read nutrition panels on food labels suggests that these consumers did not consider the level of reduction in fat intake achieved by using LFAs in deciding whether to consume these products.

Although about one quarter of subjects recognized that there was a relationship between fat and energy content, they tended not to associate fat with 'energy'. This may be one reason that so few were aware of the recommendations for fat expressed as a proportion of energy intake. Hence, while subjects seemed to be getting the message that too much fat is 'bad for you', the role of fat in energy intake was not well understood. The fact that energy was also sometimes viewed as an outcome (e.g. feeling more 'energetic' after eating low-fat foods) may explain why some subjects believed there was more energy in LFAs than regular products.

While eliminating or reducing the use of fat spreads was one of the most common recent dietary changes, more than one quarter of subjects in the present study indicated that substitution of one fat or oil for another was one of their strategies for reducing fat intake. A survey of Canadian shoppers found that $76 \%$ of respondents apparently did not understand that a low in saturated fat' claim did not necessarily mean that the product was 'low in total fat' ${ }^{25}$. The findings of both surveys suggest a lack of understanding of the distinction between fat content and fat composition.

There is also evidence from the US that general nutritional considerations, including energy intake ${ }^{12,26}$, are sometimes neglected in the pursuit of low-fat diets. Data from the current study suggest that few subjects considered energy balance in food selection, even when trying to lose weight. Further research is required to investigate the extent, if any, to which the dietary behaviour, knowledge and interpretations of nutrition advice and concepts observed in this study are typical of those of the general population.

\section{References}

1 Health Department of Victoria. Victorian Food and Nutrition Policy. Melbourne: Government Printer, 1987.

2 Kristal AR, White E, Shattuck AL, Curry S, Anderson GL, Fowler A, et al. Long term maintenance of a low fat diet: durability of fat-related dietary habits in the Women's Health Trial. J. Am. Diet. Assoc. 1992; 92: 553-9.

3 Baghurst KI, Crawford DA, Worsley A, Record SJ. The Victorian Nutrition Survey: intakes and sources of dietary fats and cholesterol in the Victorian population. Med. J. Aust. 1988; 149: 12-20.

4 Dobson A, Porteous J, McElduff P, Alexander H. Whose diet has changed? Aust. NZ J. Public Health 1997; 21: 147-54.

5 Mela DJ. Consumer estimates of the percentage energy from fat in common foods. Eur. J. Clin. Nutr. 1993; 47: 735-40.

6 Cremer SA, Kessler LG. The fat and fibre content of foods: what Americans know. J. Nutr. Educ. 1992; 24: 149-52.

7 Shepherd R, Stockley L. Nutrition knowledge, attitudes and fat consumption. J. Am. Diet. Assoc. 1987; 87: 615-19.

8 Kristal AR, Bowen DJ, Curry SJ, Shattuck AL, Henry HJ. Nutrition knowledge, attitudes and perceived norms as correlates of selecting low-fat diets. Health Educ. Res. 1990; 2: 467-77.

9 Lloyd HM, Paisley CM, Mela DJ. Barriers to the adoption of reduced fat diets in a UK population. J. Am. Diet. Assoc. 1995; 95: 553-9.

10 Lloyd HM, Paisley CM, Mela DJ. Changing to a low fat diet: attitudes and beliefs of UK consumers. Eur. J. Clin. Nutr. 1993; 47: 361-73.

11 Mela DJ. Understanding fat preference and consumption: applications of behavioural sciences to a nutritional problem. Proc. Nutr. Soc. 1995; 54: 453-64.

12 Glanz K, Brug J, van Assema P. Are awareness of dietary fat intake and actual fat consumption associated? - A DutchAmerican comparison. Eur. J. Clin. Nutr. 1997; 51: 542-7.

13 Allred JB. Too much of a good thing? J. Am. Diet. Assoc. 1995; 95: 417-8.

14 Plous S, Chesne RB, McDowell AV. Nutrition knowledge and attitudes of cardiac patients. J. Am. Diet. Assoc. 1995; 95: 442-6.

15 Schapira DV, Kurmar NB, Lyman GH, McMillan SC. The value of current nutrition information. Prev. Med. 1990; 19: 45-53. 
16 Wheeler CE, Rutishauser IHE, O'Dea K. Reproducibility of a meal-based food frequency questionnaire: the influence of format and time interval between questions. Eur. J. Clin. Nutr. 1994; 48: 795-809.

17 Wheeler CE, Rutishauser IHE, O'Dea K. Comparison of nutrient intake data from two food frequency questionnaires and weighed records. Aust. J. Nutr. Diet. 1995; 52: 140-8.

18 Australian Bureau of Statistics. 1995 National Health Survey Summary of Results Australia, Catalogue No. 4364.0. Canberra: ABS, 1997.

19 Warwick PM. Predicting food energy requirements from estimates of energy expenditure. In: Truswell AS, ed. Recommended Nutrient Intakes: Australian Papers. Sydney: Australian Professional Publications, 1990: 295-320.

20 Goldberg GR, Black AE, Jebb SA, Cole TJ, Murgatroyd PR, Coward WA, et al. Critical evaluation of energy intake data using fundamental principles of energy physiology: derivation of cut-off limits to identify under-recording. Eur. J. Clin. Nutr. 1991; 45: 569-81.
21 Australian Bureau of Statistics. National Nutrition Survey Nutrient Intakes and Physical Measurements Australia, 1995, Catalogue No. 4805.0. Canberra: ABS, 1998.

22 Fricker J, Baelde D, Igoin-Apfelbaum JMH, Apfelbaum M. Underreporting of food intake in obese 'small eaters'. Appetite 1992; 19: 273-83.

23 Hirvonen T, Mannisto S, Roos E, Pietinen P. Increasing prevalence of underreporting does not necessarily distort dietary surveys. Eur. J. Clin. Nutr. 1997; 51: 297-301.

24 Briefel RR, Sempos CT, McDowell MA, Chien S, Alaimo K. Dietary methods research in the third National Health and Nutrition Examination Survey: underreporting of energy intake. Am. J. Clin. Nutr. 1997; 65: 1203S-9S.

25 Reid DJ, Hendricks SM. Consumer understanding and use of fat and cholesterol information on food labels. Can.J. Public Health 1994; 85: 334-7.

26 Schwartz NE, Borra ST. What do consumers really think about dietary fat? J. Am. Diet. Assoc. 1997; 97 (Suppl.): S73-5. 